\title{
Comparative Analytic of Viscoelasticity Carbon, Glass, and Graphite Fiber Composite Using Maxwell Model
}

\author{
Ro'sil Khohar ${ }^{1, a}$, Umi Sa'adah ${ }^{1}$ and Dewi Azzahra Puspita ${ }^{1}$ \\ ${ }^{1}$ Fisika, Fakultas Matematika dan IImu Pengetahuan Alam Universitas Jember, Indonesia \\ arosilqohhar46@gmail.com
}

\begin{abstract}
The fulfillment of the need for materials with viscoelastic characteristics to be a supporting factor. The aim is to obtain composite materials with good viscoelasticity. Vinylester matrix composite materials with variations of graphite, glass, and carbon fibers were tested using FEA and Maxwell model. The simulated viscoelasticity of the isotropic, transverse, and mixed state of glass, carbon, and graphite fibers depends on the magnitude of modulus Young and Poisson's ratio. The most significant sequence value of viscoelasticity is in graphite fiber $10.4 \mathrm{GPa}$, carbon $5.5 \mathrm{GPa}$ fiber, and glass fiber $3.78 \mathrm{GPa}$.
\end{abstract}

Keywords: Viscoelastic, FEA method, Maxwell Model

\section{Introduction}

Currently, the development of materials technology is growing rapidly. Fulfilling the need for materials with specific composite characteristics is also a driving factor. Various kinds of materials have been used, and further research is also being done to get the functional materials, one of which is polymer composite materials. Its ability to be easily shaped as needed, both in terms of strength and other advantages, encourages the use of polymer composite materials as alternative materials or substitutes for conventional metal materials in various products produced by industries, especially the manufacturing industry [1].

Composite materials are materials that are composed of a combination of two or more primary elements that differ in the macro form or composition of materials, which are inseparable [2]. The advantages of composite materials compared to the metals are corrosion resistance or resistance to the influence of the free environment. For certain types of composites, it has better strength and stiffness. Therefore, continuous research is directly proportional to the technology development of these materials, especially composites. The development of composites is not only from synthetic composites but also from renewable natural composites, thereby reducing the environmental pollution. Research on composite materials and components made of composite materials has been widely carried out.

Several studies discuss the characteristics of composite materials based on their viscoelastic. However, none of these studies have compared the characteristics of composites that are reinforced with graphite fibers, glass fibers, and carbon fibers. This argument encourages researchers to conduct further research.

In this study, the characteristics of the composite that want to be known are the stiffness, strength, and density of the composite reinforced with glass fiber, graphite fiber, and carbon fiber. This statement causes researchers to want to obtain composite materials that are strong, stiff, durable, and also lightweight. So, We must be able to determine the characteristics of the appropriate polymer composites, namely the tensile test and density test. From the background 
above, the problem raised in this journal is how the characteristics and comparison of fiberreinforced composite materials from three materials in the form of glass fiber, graphite fiber, and carbon fiber using the Maxwell model.

The objective of this research is that the researcher wants to know and characterize the composite material reinforced with glass fiber, graphite fiber, and carbon fiber as an alternative to industrial raw materials. The benefits of this research can be used in the Maxwell modeling field and also carried out to determine the characteristics of the effect of variations in the elasticity fraction of the three types of composites. The modeling knows the comparison of the characteristics of the composite structure with each other, understands the composites with characteristics that are close to ideal and also know which composites can be used as alternative materials, the industrial raw material on graphite, glass, and carbon fibers.

A composite material is a material consisting of two or more different materials that are combined or mixed macroscopically into a useful material [3]. The composite materials are combined materials. In macro terms, the composite material can be defined as a material system composed of a mixture/combination of two or more different main elements. The composition of this composite constituent material can no longer be separated [6]. Composites produced by an agency or factory can usually predict the mechanical properties of the composite materials based on the matrix and reinforcing materials [4].

Viscoelastic is a property of a material to test strain, stress, and strength in a material. The response of each material to a given external load depends on the properties of the material. Materials whose behavior is influenced by a function of time are called viscoelastic materials. Equations can explain the time-dependent behavior of viscoelastic materials with variables of stress, change in shape, and time. The magnitude of the tensile strength produced by polymer/fiber composites can be predicted using equation 2.1. Based on this equation, it can be used by researchers to determine the extent of the tensile strength produced by the composite based on the fundamental matrix and reinforcement. Here is the viscoelasticity equation:

$\hat{E}_{m}=1 / \hat{D}_{m}=\frac{s \eta_{m} E_{m}}{E_{m}+s \eta_{m}}=\frac{s E_{m}}{E_{m} / \eta_{m}+s}$

Graphite is the carbon atoms connecting each other into sheets, and graphite is the most stable form of carbon. Graphite is soft but very strong. It is resistant to heat and, at the same time, a conductor of heat. Found in metamorphic rocks, it appears as a metallic but opaque substance with a color that varies from dark gray to black.

Glass fibers have different characteristics from one another. In its use, glass fibers are adjusted according to their properties or characteristics. Glass fibers are made of silica, alumina, lime, magnesia, and others. The advantage of glass fiber lies in the ratio (comparison) of price and performance, namely low production costs, very simple production processes. Glass fibers are widely used in the automotive industries such as in-vehicle body panels. Even motorbikes are now all body made of glass fiber reinforced composites. Glass-epoxy and glass-polyester composites are also applied to ship hulls and aircraft parts. 
Carbon fiber serves as a reinforcing material in carbon fiber composites. As for the matrix, polymer resins such as epoxy are usually used. This resin matrix serves to bind the reinforcing elements. Because carbon fiber is only composed of these two materials, the properties of carbon fiber are also solely determined by these two materials. Both being very light and strong is one of the advantages of carbon fiber composites.

\section{Method}

This study aims to determine the viscoelasticity ratio of graphite, glass, and carbon fibers. Finite Element Analysis (FEA) is carried out in several stages as follows. First, idealization, which is changing physical problems into a model. In modeling, there will be idealization or simplification because the physical problems that do occur are often very complex. Also, idealization and simplification occur in defining boundary conditions such as working load and the amount of displacement on support. Shipments that do not change significantly with time are usually idealized as static loads. The load can also be modeled in the form of concentrated load, distributed load, or both combined. The support can also be modeled as a support die, hinge, or roller. Maxwell model is used for a creep test at the end of the model with constant stress, as shown in Figure 1.

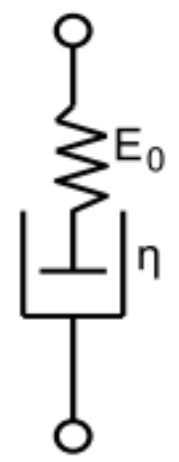

Figure 1. Maxwell Model

The Laplace transform is used to derive relaxation from Maxwell's model,

Table 1. Laplace transform

\begin{tabular}{ccc}
\hline Function & $\boldsymbol{f}(\boldsymbol{t})=\boldsymbol{L}^{-1}\{\boldsymbol{f}(\boldsymbol{s})\}$ & $\boldsymbol{f}(\boldsymbol{t})=\boldsymbol{L}\{\boldsymbol{f}(\boldsymbol{s})\}$ \\
\hline Constant & $a$ & $a / s$ \\
Linier & $a t$ & $a / s^{2}$ \\
Derivative & $d f / d t$ & $s f(s)-f(0)$ \\
Exponential & $\exp (a t)$ & $1 /(s-a)$ \\
Convolution integral & $\int_{0}^{l} f(t-\tau) g(\tau) d \tau$ & $L\{f\} L\{g\}$ \\
& & \\
\hline
\end{tabular}

Then with the inverse Laplace transform, relaxation is obtained in the time domain:

$$
E(t)=E_{0} \exp (-t / \tau)
$$


where $t=\tau$ (material time constant)

The research flowchart of this journal can be seen in Figure 2.

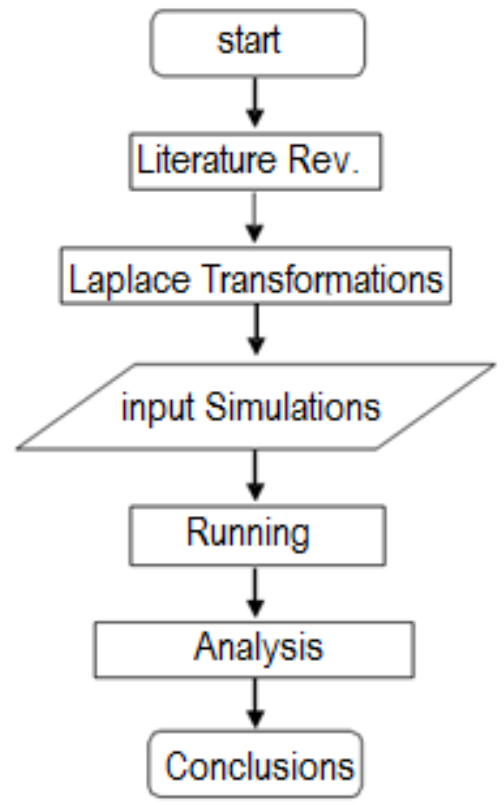

Figure 2. The research flowchart

\section{Boundary conditions and parameters}

The following are the boundary conditions and parameters used in the simulation process.

1. Characteristics of Vinylester

Young's Modulus (Ef 3,78 GPa)

Poisson's Ratio (nu_f 0.35)

Density (1160 kg / m3)

2. Characteristics of Graphite

Young's Modulus (Ef $45 \mathrm{GPa}$ )

Poisson's Ratio (nu_f 0,3)

Density $\left(641 \mathrm{~kg} / \mathrm{m}^{3}\right)$

3. Karakteristik Kaca

Young's Modulus (Ef $45 \mathrm{GPa}$ )

Poisson's Ratio (nu_f 0,3)

Density $\left(2000 \mathrm{~kg} / \mathrm{m}^{\overline{3}}\right)$

4. Karakteristik Karbon

Young's Modulus (Ef 133,86 GPa) 


\section{Computational and Experimental Research in Materials and Renewable Energy (CERiMRE)

Poisson's Ratio (nu_f 0,3 )

Density $\left(1520 \mathrm{~kg} / \mathrm{m}^{\overline{3}}\right)$

\section{Results and Discussion}

A load that has high stiffness when it is subjected to load (within its elastic limit) will experience elastic deformation but only slightly. The modulus of elasticity usually indicates the stiffness of a material. The higher the modulus of elasticity of the composite, the stiffer the composite material will be. In this study, a graph of the value of elasticity and viscoelasticity was obtained for each fiber.

Graph of the elasticity and viscoelasticity of the transverse modulus of graphite fibrous composites can be seen in Figure 3.

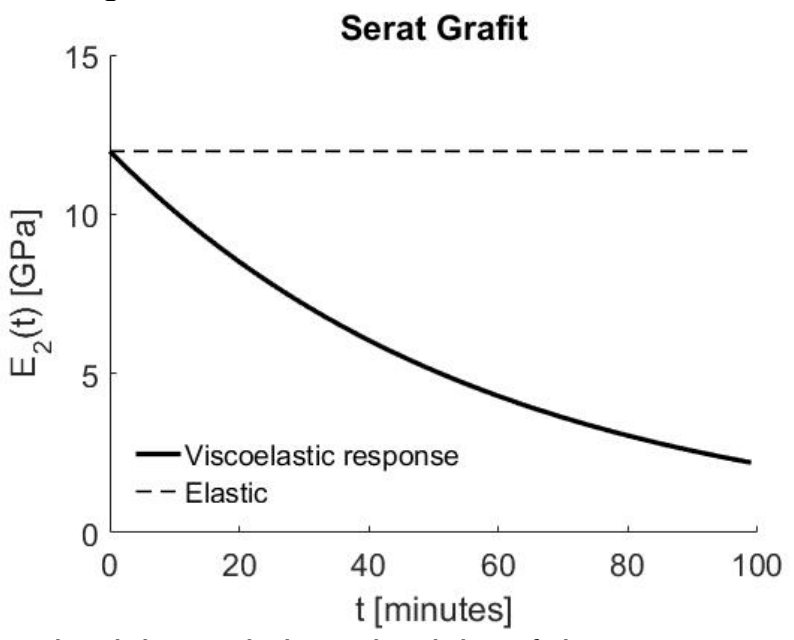

Figure 3. Graph of the elasticity and viscoelasticity of the transverse modulus $E_{2}$ of graphite fibrous composites

Based on the figure, it can be seen that the elasticity of the graphite fiber is in the range of 10$15 \mathrm{GPa}$, which is about $10.4 \mathrm{GPa}$. Meanwhile, the viscoelasticity response to time for graphite fibers is decreasing.

The glass fiber material is one type of composite fiber that has the advantage of being strong but still light. In fiberglass composites, the reinforcing component is glass fibers. The glass that we know every day has properties that are easily cracked and broken, this is since the hardness of the glass surface is too high, making it easier for the crack propagation process on the glass surface even with a slight defect or load. To avoid initial cracks or defects on the glass surface, the glass is made of very thin threads with a diameter of about 5-25 micrometers.

The graph of the elasticity and viscoelasticity of the transverse modulus of glass-fibrous composites can be seen in Figure 4. 


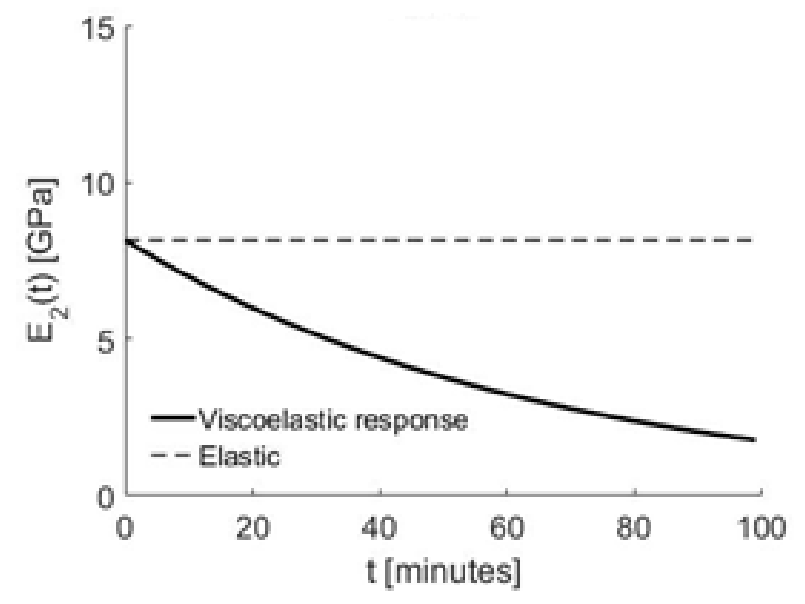

Figure 4. The elasticity and viscoelasticity values of the transverse modulus $E_{2}$ of glass-fibrous composites

Based on the figure, it can be seen that the elasticity of the glass is between 5-10 GPa or about $3.78 \mathrm{GPa}$. Meanwhile, the viscoelasticity response of glass fibers to time changes is decreasing. Carbon fiber is a form of composite material. Composite materials are composed of two main components, namely the matrix and the reinforcing material. Carbon fiber serves as a reinforcing material, while the matrix is usually used polymer resins such as epoxy. Several factors influence the properties of carbon fiber. One of the most important factors is the direction or groove of the carbon fiber.

The graph of the elasticity and viscoelasticity of the transverse modulus of carbon fiber composites can be seen in Figure 5.

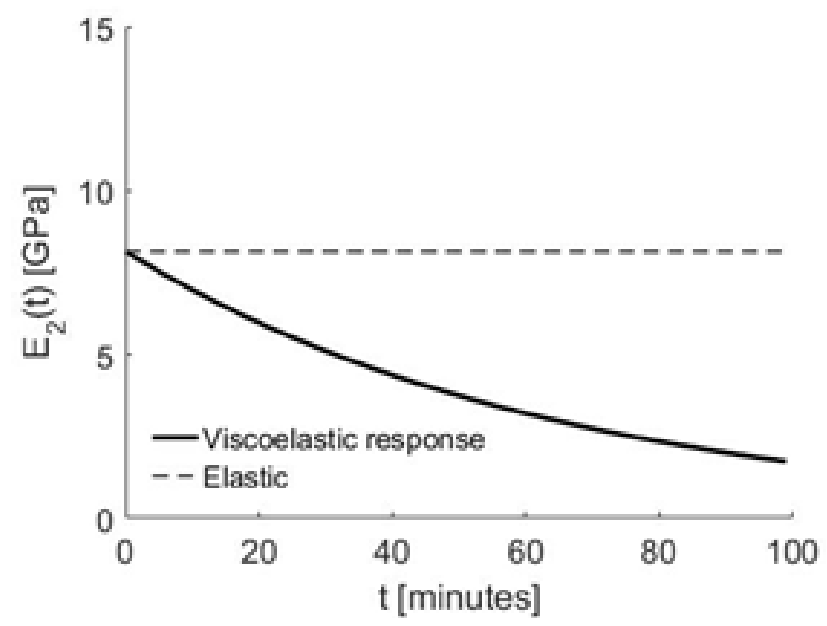

Figure 5. Graph of the elasticity and viscoelasticity of the transverse modulus of carbon fiber composites 
Based on this figure, it can be seen that the elasticity of carbon fibers is almost the same as the elasticity of glass fibers, which is about $5.5 \mathrm{GPa}$. However, the viscoelasticity response to time for carbon fibers is lower than for glass fibers.

Based on the graph of the three graphite, glass, and carbon fibers, it can be seen that the elasticity of the material remains constant. In contrast, the viscoelasticity of the material decreases. Carbon fiber has the lowest viscoelasticity response value compared to graphite and glass fibers. The viscoelasticity value does not depend on the size of the object but only depends on the type of object.

\section{Conclusions}

The viscoelasticity that has been simulated in isotropic, transverse, and mixed states of glass fiber, carbon, and graphite depends on the size of Young's modulus and Poisson's ratio. The value of the order of the greatest viscoelasticity is in graphite fiber, carbon fiber, and glass fiber.

\section{References}

[1] D A Porwanto, and L Johar, 2003, Karakterisasi Komposit Berpenguat Serat Bambu dan Serat Gelas Sebagai Alternatif Bahan Baku Industri, Surabaya, ITS.

[2] M M Schwartz, 1984, Composite Material Handbook, New York: McGraw Hill Inc.

[3] J W D Callister, 2007, an Introduction Material Science and Engineering, United States of America Quebecor Versailles.

[4] P M Jones, 1975, Mechanics Of Composite Materials Institute Of Technology, Southern Methodist University, Mc. Graw-Hill, Dallas.

[5] E J Barbero, 2014, Finite Element Analysis of Composite Materials Using Ansys, CRS Press, Taylor \& Francis Group. 